\title{
Design of CPW Band Notch Slot UWB Antenna at 8.7 and 10.2 GHz for Wireless Broadband Applications
}

\author{
Barun Kumar \\ PhD. Scholar \\ MANIT, Bhopal
}

\author{
Ajay Somkuwar \\ Professor \\ MANIT, Bhopal
}

\author{
Deepak K. Raguvanshi \\ Assistant Professor \\ MANIT, Bhopal
}

\begin{abstract}
The characteristics of the proposed antennas have been investigated through computer simulation for Ultra wideband (UWB) application. The proposed antenna has achieved good impedance matching, consistent gain, stable radiation patterns and consistent group delay over operating frequency band. A coplanar waveguide (CPW)fed ultra wide band antenna is presented. The UWB antenna consists of a rectangular patch, which is etched onto an FR4 printed circuit board(PCB) with an overall size of $30 \mathrm{mmX} 35 \mathrm{mmX} 1 \mathrm{~mm}$. The simulation shows that the UWB antenna achieves good impedance matching, consistent of gain, and enhancing the operating bandwidth. The correlation between the mode-based $\mathrm{fie}$ id distributions is discussed. Extended from the UWB antenna, three notch designs are also presented as a desirable feature for UWB application at $8.7 \& 10.2 \mathrm{GHz}$.
\end{abstract}

\section{Keywords}

Band-notched characteristics, CPW-fed UWB antennas, Return loss, PCB, Slot, Y-parameters, z-parameters.

\section{INTRODUCTION}

Ultra Wide Band (UWB), one of the core technologies in wireless personal area networks (WPANs) have maximum growth in recent years . UWB antenna with transmission rates up to $500 \mathrm{Mbps}$ have been developed and demonstrated. The inherently ultra-wide operating bandwidth from $3.1 \mathrm{GHz}$ to $10.6 \mathrm{GHz}$, An ultra-wideband antenna involves considerable extra design constraints. In such a system the antenna behaves more like a band pass filter in both spatial and frequency domains. Any no ideal variation of the antenna response will inevitably introduce signal distortion and hence seriously deteriorate the overall performance. Various researchers have been devoted themselves to investigating the descriptions, analyses, and optimizations of ultra-wideband antennas in either time domain or frequency domain . and novel antenna designs have been successfully demonstrated in the literatures as well. Among those newly proposed Ultrawideband antennas, the planar monopole antennas should be the most fascinating candidate for future application due to their remarkably compact size and stable radiation characteristics. It is desirable to design the UWB antenna with a notched band at to minimize the potential interference. In this paper, a coplanar waveguide(CPW)fed rectangular slot antenna with T-shaped stub is presented. The UWB antenna is successfully designed and verified. The antenna performs promising characteristics on the impedance matching, gain and group delay over the entire UWB band. In this paper, the UWB antenna is further extended to the band-notched function. The design concept described and two different bandnotched designs provided for illustration. It shows that successful band- rejection capability for both band-notched designs.

\section{RESEARCH METHODOLOGY}

The parametric study is carried out to provide antenna engineers with more details of the antenna and a guideline for antenna optimization. The impedance bandwidth of $-10 \mathrm{~dB}$ return loss is investigated. It has been found that the operating band of the antenna is mainly determined by the width and length of the radiating element. The remaining parameters do not show significant effect on the impedance bandwidth but can be optimized to improve the impedance matching. To well understand the influence of these parameters on the impedance bandwidth, only one parameter is investigated at a time whereas the others are kept invariant unless especially indicated. Figure. 2 Shows the effect of isolated slot, on the impedance bandwidth of the antenna. It is observed that the operating band of the antenna is much dependent on the width of the slot, the operating band shifts down. Figure. 3 exhibits the effect of the open-end slot, on the impedance matching. The best performance is obtained with optimized $\mathrm{L}(15 \mathrm{~mm})$. These results suggest that the proposed antenna features typical wide-slot antenna characteristics, namely the width of the patch is the key factor to determine the operating bandwidth of the antenna. The length of the patch shows slight effect on the bandwidth whereas it can be optimized to achieve specified impedance matching. The band-notch function is desirable in the UWB sys- tem to reduce the interferences with the IEEE802.11a, b, c and WLAN systems . In this paper, two kinds of band-notch designs are presented. The Figure.2,3 shows the geometry and dimensions of these designs. The first design embeds an isolated slit of total length equal to half a wavelength for the frequency at $8.5 \mathrm{GHz}$ inside the $\mathrm{T}$-stub as shown in Figure. 2 . The second design employs two open-end slits at the top edge of the T-stub, as shown in Figure.3. Where the effective length of each slit is around quarter wavelength for the $8.5 \mathrm{GHz}$ resonance. Note that when the band-notched design applied to antenna. There is no retuning work required for the previously determined dimensions. Generally, the design concept of the notch function is to adjust the total length of the slits to be approximately half-wavelength at the desired notched frequency, which makes the input impedance singular at the sub-resonant frequency. To implement it, a narrow-band resonant structure is added to the original wide-band antenna area. Based on this concept, the above two designs using the isolated slit, the open-end slits as illustrated in Figure.(3)-(4). . The notch frequency given the dimensions of the band notched design can be postulated as

$$
\text { Fnotch }=\frac{c}{2 L \sqrt{\varepsilon e f f}}
$$

Where $\mathrm{L}$ is the total length of the slits $\varepsilon_{e f f}$ is the effective dielectric constant and $\mathrm{c}$ is the speed of the light. 
We can take (eq. 1) into account in obtaining the total length of the slits at the very beginning of the design and the adjust the geometry for the final design. Performance of the simulated Return Loss four kind of band notch antennas are shown in Figure.4.

\section{PROPOSED WORK}

Figure.1 shows the geometry and configuration of a UWB antenna. The antenna was fabricated on an $\mathrm{h}=1 \mathrm{~mm}$ FR4 epoxy substrate with dielectric constant $\varepsilon r=4.4$ and loss tangent $\tan \delta=0.02$. As shown in the figure, a rectangular radiator is fed by a $50 \Omega$ coplanar waveguide (CPW) transmission line. Since both the antenna and the feeding are implemented on the same plane, only one layer of substrate with single-side metallization is used. And the manufacturing of the antenna is very easy and extremely low cost. The IE3D-v-14.65 is employed to perform the design and optimization process. The first design embeds an isolated slit of total length equal to half a wavelength for the frequency at $8.7 \mathrm{GHz}$ inside the T-stub as shown in Figure. 2 The second design employs two open-end slits at the top edge of the Tstub, as shown in Figure.3. Where the effective length of each slit is around quarter wavelength for the $8.7 \mathrm{GHz}$ resonance.

Table-I-Antenna Parameters

\begin{tabular}{|c|c|c|c|}
\hline $\begin{array}{c}\text { Substrate } \\
\text { Thickness }\end{array}$ & $1.1 \mathrm{~mm}$ & $\begin{array}{c}\text { Dielectric } \\
\text { Constant, } \varepsilon_{r}\end{array}$ & 4.4 \\
\hline $\begin{array}{c}\text { Patch } \\
\text { Length, L }\end{array}$ & $34 \mathrm{~mm}$ & Patch Width, W & $32 \mathrm{~mm}$ \\
\hline $\begin{array}{c}\text { Inset Width, } \\
\text { S }\end{array}$ & $8 \mathrm{~mm}$ & Inset Depth, D & $15 \mathrm{~mm}$ \\
\hline $\begin{array}{c}\text { Strip Width, } \\
\text { T }\end{array}$ & $7 \mathrm{~mm}$ & $\begin{array}{c}\text { Feed Line Length, } \\
\text { F }\end{array}$ & $15 \mathrm{~mm}$ \\
\hline Slot width, w & $14 \mathrm{~mm}$ & Slot length, $\mathrm{l}$ & $23 \mathrm{~mm}$ \\
\hline
\end{tabular}

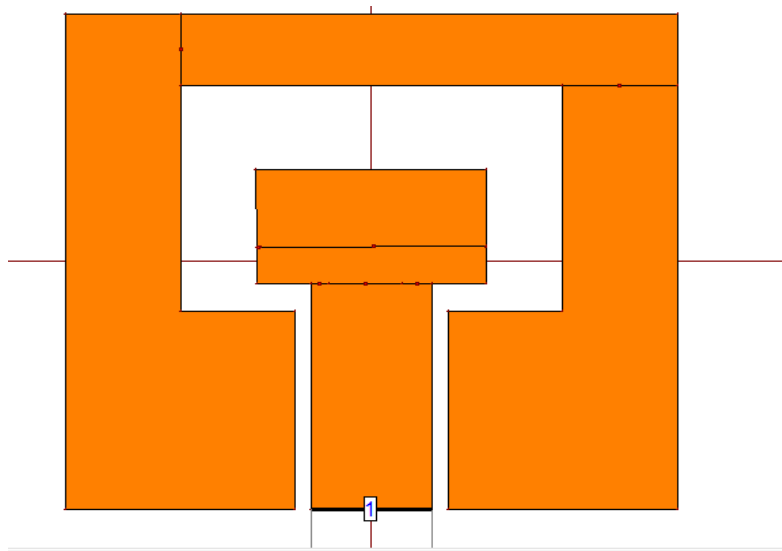

Fig-1-Design of antenna (slot-1)

\section{VSWR CALCULATION}

The voltage component of a standing wave in a uniform transmission line consists of the forward wave (with amplitude $V_{f}$ ) superimposed on the reflected wave (with amplitude $V_{r}$ ). Reflections occur as a result of discontinuities, such as an imperfection in an otherwise uniform transmission line, or when a transmission line is terminated with other than its characteristic impedance. The reflection coefficient $\Gamma$ is defined thus:

$\Gamma=\frac{V r}{V f}$

For the calculation of VSWR, only the magnitude of $\Gamma$, denoted by $\rho$, is of interest. Therefore, we define $\rho=|\Gamma|$.

At some points along the line the two waves interfere constructively, and the resulting amplitude $V_{\max }$ is the sum of their amplitudes:

$V \max =V r+V f=V f+\rho V f=V f(1+\rho)$

At other points, the waves interfere destructively, and the resulting amplitude $V_{\min }$ is the difference between theiramplitudes

$V \min =V f-V r=V f-\rho V f=V f(1-\rho)$

The voltage standing wave ratio is then

$$
V S W R=\frac{V \max }{V \min }=\frac{1+\rho}{1-\rho}
$$

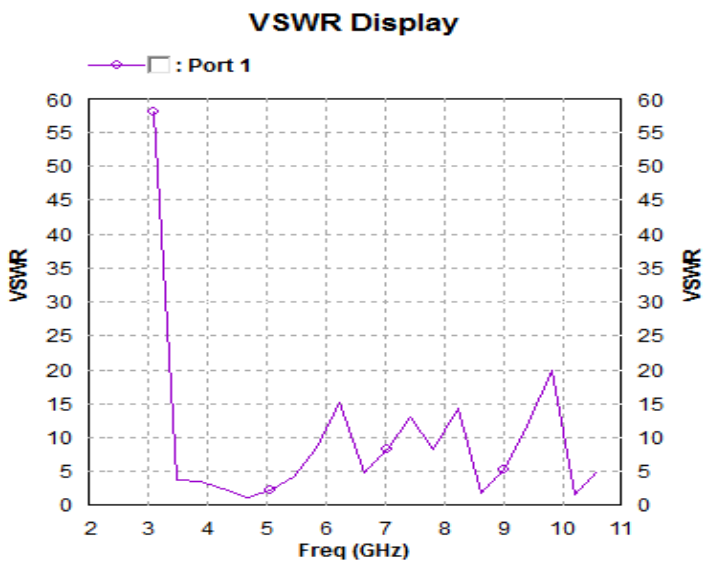

VSWR Vs Frequency

As $\rho$, the magnitude of $\Gamma$, always falls in the range [0,1], the VSWR is always $\geq+1$.

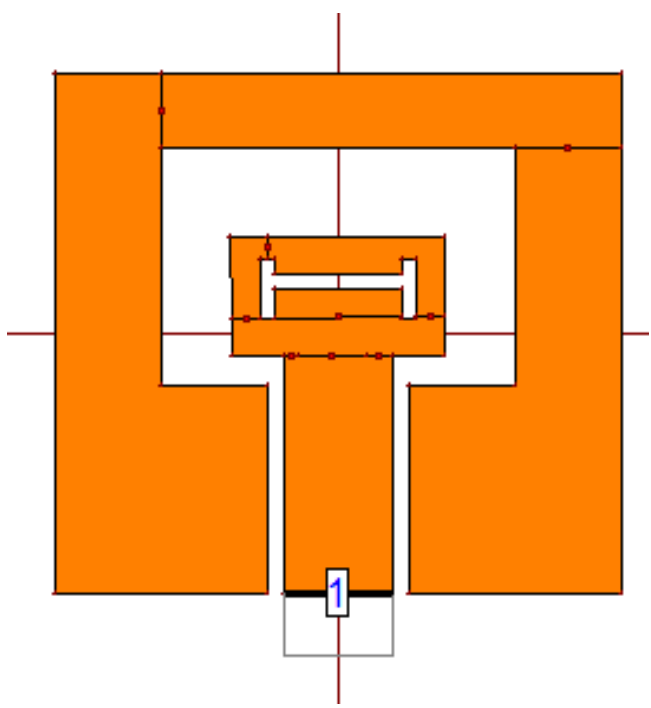

Fig-2-Design of Isolated Slot Antenna (slot-2) 


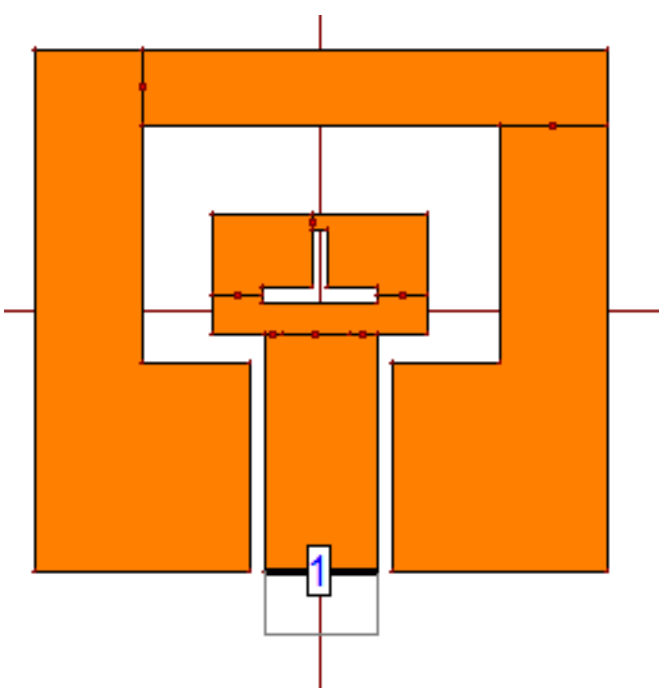

Fig-3-Design of Open Slot Antenna (slot-3)

\section{S-Parameters Display}
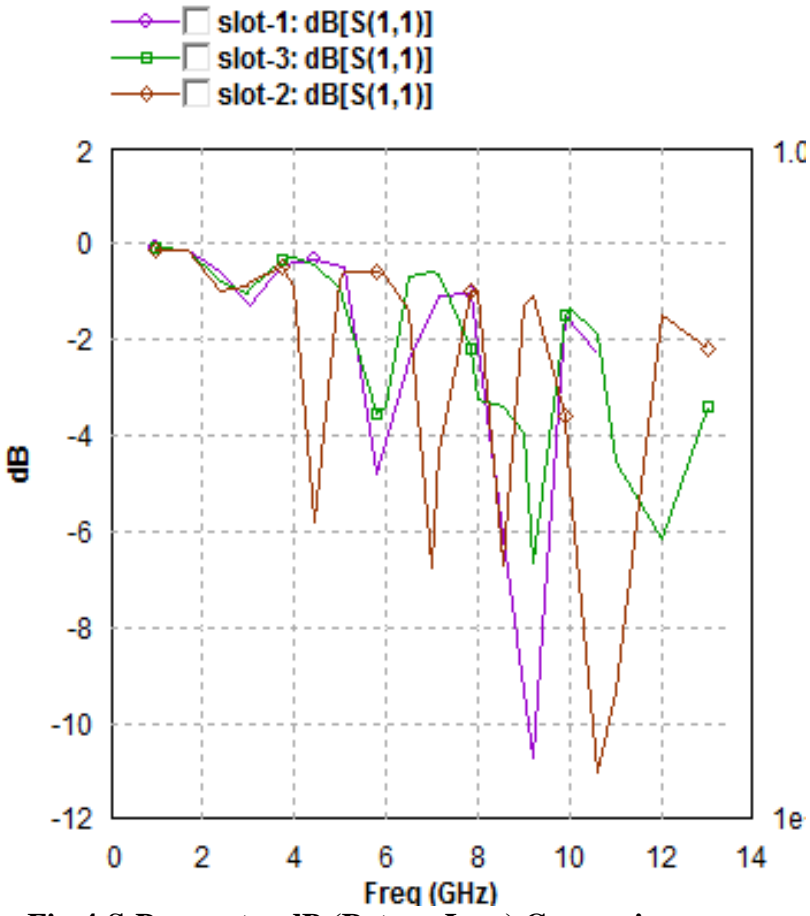

Fig-4-S-Parameter dB (Return Loss) Comparison

\section{Y-Parameters Display}

$\multimap$ slot-1: $\operatorname{Mag}[\mathrm{Y}(1,1)]$

$\smile$ ¿ slot-2: Mag[Y(1,1)]

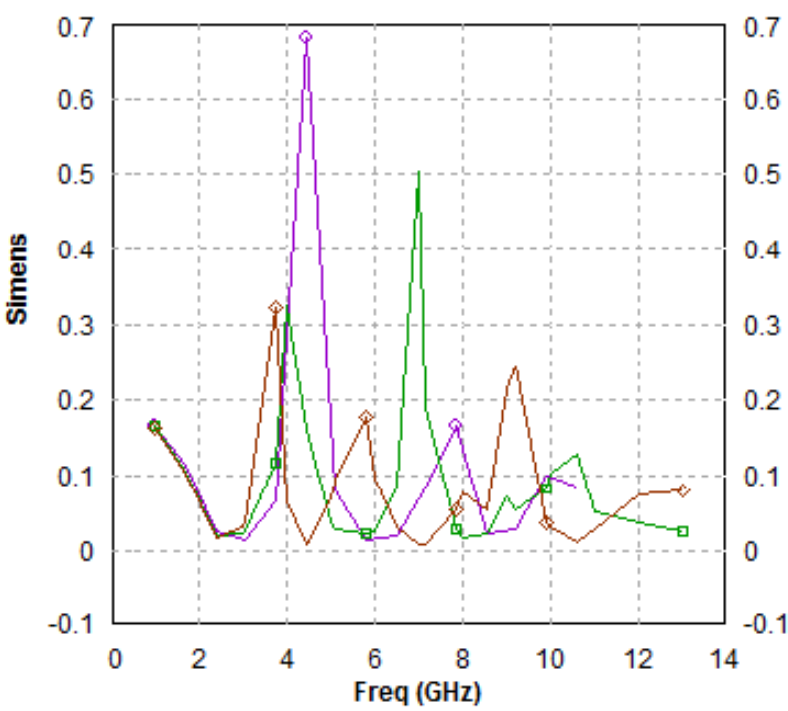

Fig-5-Y-parameter Comparison

Z-Parameters Display

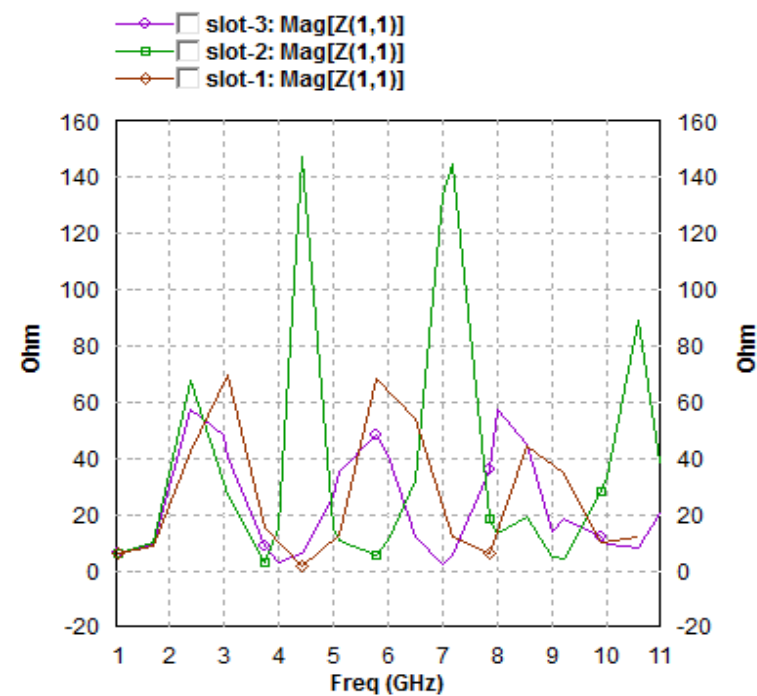

Fig-6-Z-Parameter Comparison

\section{CONCLUSION}

Furthermore, an extended four band-notched design has been proposed with the desired performance over low/high UWB bands and notched band of $8-10 \mathrm{GHz}$. The band notched characteristics can be controlled by adjusting length and width of the slit, whereas no returning of the original design is required. The parametric study has addressed the most sensitive parameters in the proposed antenna designs. The return loss (s parameters S11), are also measured and compare by using an HP8510C vector network analyzer and the result are very well correlated with computer. 


\section{REFERENCES}

[1] Ying-Ying Yang,Qing-Xin Chu, and Zhi-An Zheng "Time Domain Characteristics of Band-Notched Ultrawideband An- tenna," IEEE Trans. Antennas Propag., vol.57, pp3426-30, Oct2010.

[2] Jung N.Lee,Ji H.Kim,Jong K.Park, and Jin S.Kim , "Design of dual-band antenna with U-shaped open stub for WLAN/UWB Application," Microwave and Optical Technology Letters , vol.51,pp.284289,Feb.2009.

[3] Wen-Piao Lin and Chao-Hsiang Huang, "Coplanar waveguide- fed rectangular antenna with an inverted-L stub for ultrawide- band communication," IEEE Antenna and Wireless Propag., Letters, vol.8, pp227231, May 2009

[4] Qing-Xin Chu and Ying-Ying Yang, "A compact ultrawide- band antenna with $3.4 / 5.5 \mathrm{GHz}$ dual band notched character- istics," IEEE Trans. Antennas Propag.,vol.56, pp3637-3644, Dec.2008.

[5] HUNG, K.-J., LIN, Y.-CH. Open-slot loaded monopole antennas for WLAN and UWB applications. In IEEE Antennas and Propagation Society International Symposium. Albuquerque (USA), 2006, p. 4653 - 4656.

[6] ABBOSH, A. Planar ultra wideband antennas with rejected sub bands. In IEEE Proceedings of Asia-Pacific Microwave Conference. Bangkok (Thailand), 2007.

[7] Zeland IE3D v14.65 simulation software, www.zeland.com.
[8] L. Li, X. Zhang, X. Yin, and L. Zhou, "A compact tripleband printed monopole antenna for WLAN/WiMAX applications," IEEE Antennas and Wireless Propagation Letters, vol. 15, 2016.

[9] A. Sharma, G. Das, and R. k. Gangwar, "Tri-band ring dielectric resonator based integrated antenna for WLAN/WiMAX applications," Proc. IEEE CAMA, 2017.

[10] M. Shuhrawardy, M. H. M. Chowdhury, and R. Azim, "Design of a compact triple-band antenna for WLAN/WiMAX applications," IEEE Int. Conf. Electrical Information and Communication Technology (EICT), Dec. 2017.

[11] F. Liu, K. Xu, P. Zhao, L. Dong, and G. Wang, "Uniplanar dual-band printed compound loop antenna for WLAN/WiMAX applications," Electronics Letters , vol. 53, no. 16, pp. 1083-1084, Aug. 2017.

[12] K. Pedram, J. Nourinia, and C. Ghobadi, "A small dual band antenna with simple structure for WLAN/WIMAX application," Int. Symposium on Telecommunications, 2016.

[13] S. Biswas, C. K. Ghosh, "Harmonic suppression of microstrip patch antenna using Defected Ground Structure," IEEE Antennas and Wireless Propagation Letters, 2016.

[14] R. Mishra, P. Kuchhal, "Effect of height of substrate and width of patch on the performance characteristics of patch antenna." IEEE Antennas and Wireless Propagation Letters, 2015 